DE

M E D I C I N A

T R O P I C A L

$\mathrm{DE}$

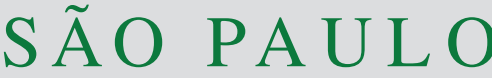

JOURNAL OF THE SÃO PAULO INSTITUTE OF TROPICAL MEDICINE

'Universidade Federal Fluminense, Faculdade de Medicina, Departamento de Patologia, Niterói, Rio de Janeiro, Brazil

2Universidade Federal do Rio de Janeiro, Instituto de Microbiologia Prof. Paulo de Góes, Rio de Janeiro, Rio de Janeiro, Brazil

Correspondence to: José Mauro Peralta Universidade Federal do Rio de Janeiro, Instituto de Microbiologia Prof. Paulo de Góes, Av. Carlos Chagas Filho, 373, CCS - BL. I, sala 046, Cidade Universitaria, CEP 21941904, Rio de Janeiro RJ, Brazil Tel: +55 21 3938-6747

E-mail: peralta@micro.ufrj.br

Received: 28 January 2019

Accepted: 24 April 2019

\section{New insights into the detection and molecular characterization of Cryptosporidium with emphasis in Brazilian studies: a review}

Flavia Souza Cunha ${ }^{1}$, José Mauro Peralta ${ }^{(12}$, Regina Helena Saramago Peralta ${ }^{1}$

\section{ABSTRACT}

Cryptosporidium spp. is a pathogenic protozoan present in the gastrointestinal tract of several hosts. This protozoan was originally classified as within the Coccidia Class and has recently been reclassified to gregarine based on studies that observed the evolutionary phases from the process of excision and sequencing of the 18S rRNA gene. Molecular biology techniques have become diagnostic tools and have also been used to understand the epidemiology of Cryptosporidium spp., since several species of this genus are very similar morphologically and morphometrically. Molecular techniques have been used in the identification of parasites, at the species and subtypes levels and to study disease transmission. The laboratory diagnosis of human cryptosporidiosis can be made by parasite detection methods, such as optical microscopy, antigens or genetic material detection, as well as serum antibodies raised to Cryptosporidium spp. Molecular methods were developed and allowed, not only an extensive revision of the taxonomy, but also an improvement in the laboratory diagnosis. In Brazil, there are few reports of Cryptosporidium spp. outbreaks in humans and all of them took place in nurseries. A few epidemiological studies developed in Brazil have used molecular methods for the detection of Cryptosporidium spp., as well as genotyping studies of their species and subtypes. The use of real-time PCR, together with microscopy and immunochromatography techniques, would result in a more precise diagnosis of cryptosporidiosis. The analysis of genotypes, subtypes and clonality of Cryptosporidium could be useful to understand and define the prognosis and severity of infections.

KEYWORDS: Cryptosporidium spp. Molecular characterization. Laboratory diagnosis. Epidemiological studies.

\section{INTRODUCTION}

Cryptosporidium spp. is a pathogenic protozoan present in the gastrointestinal tract of several hosts ${ }^{1}$. This parasite was firstly described in 1907 by Ernest Edward Tyzzer, in the gastrointestinal epithelium of mice. Human infection was first described in 1976, in a child and in an adult in the same year. Cryptosporidium spp. has been a public health concern mainly due to reports of outbreaks in day care centers, immunosuppressed patients and also in waterborne transmission reports ${ }^{2}$. Cryptosporidium spp. is one of the most prevalent waterborne parasites in the world and one of the main concerns in Public Health since the oocyst, the infecting form, is resistant to the most common disinfectants adopted in water treatment plants $\mathrm{s}^{3,4}$.

This protozoan was originally classified within the Coccidia Class $^{5}$, but has recently been reclassified to gregarine based on studies ${ }^{6-8}$ that observed the evolutionary phases from the process of excision and sequencing of the 18S rRNA 
gene. Cryptosporidium spp. presents a morphological and phylogenetic relationship closer to gregarine than to coccidia. These findings were not adequately addressed by the scientific community until Clode et al. ${ }^{9}$ summarized them so that currently, Cryptosporidium spp. is classified in the sub-class Cryptogregaria, within the Class Gregarinomorphea, which is characterized as epicellular containing organisms, a food organelle very similar to that of the gregarines (epimerite) but it does not present apicoplast ${ }^{10,11}$.

Another very relevant finding of in vitro and in vivo studies was the verification that Cryptosporidium spp. can develop its life cycle outside a host cell ${ }^{12,13}$. The possibility of Cryptosporidium spp. multiplying in biofilms, in water or sewage treatment plants, led to new challenges for the correct management of these resources in view of a greater risk of outbreaks from waterborne transmission. In addition, microbial biofilms can form in the interior of the human intestine, increasing the host's susceptibility, as well as during the course of the infection ${ }^{9}$.

Molecular biology techniques have become diagnostic tools that have been used to understand the epidemiology of many infectious agents, including Cryptosporidium spp., since several species of this genus are very similar morphologically and morphometrically. Molecular techniques have been used in the identification of parasites, at the species and subtypes levels, and in the study of disease transmission. This has had a great impact on epidemiological studies, taxonomy and classification of parasites, as well as on the understanding the pathogen's biology. According to Xiao et al. ${ }^{14}$, with the application of molecular techniques in the taxonomy, it is possible to incorporate genetic data as one of the parameters to validate the Cryptosporidium species evaluation. Today, 38 species of Cryptosporidium have been described, going from amphibian parasites to mammals ones ${ }^{15}$ (Table 1), totaling more than 40 genotypes infecting mammals, but Cryptosporidium parvum and Cryptosporidium hominis are the two species predominantly reported in human infections ${ }^{16}$. In the molecular characterization of the Cryptosporidium genotype, $18 \mathrm{~S}$ rRNA genes are the most used because they present five copies per genome and are less polymorphic due to a slower evolution, therefore being the locus of choice for animal samples that may be infected by species or genotypes not yet classified.

Analysis of the DNA sequence encoding the GP60 glycoprotein is the most commonly used method to study C. hominis subtypes in humans and C. parvum subtypes in humans and ruminants ${ }^{17}$. The $g p 60$ gene (also called gp15/40) is similar to a microsatellite sequence because it has tandem repeats of TCA, TCG or TCT trinucleotides at the end of the gene. However, in addition to variations in the number of trinucleotide replications, there are extensive differences in sequences on regions without

Table 1 - Cryptosporidium species* found in human infections.

\begin{tabular}{|c|c|c|c|}
\hline Species & Main Host & Site of infection & Reference \\
\hline C. hominis & Human & Small intestine & $\mathrm{Xiao}^{17}$ \\
\hline C. parvum & Ruminants & Small intestine & Tyzzer apud Xiao ${ }^{17}$ \\
\hline C. meleagridis & Turkey, Birds and human & Small intestine & Slavin ${ }^{86}$ \\
\hline C. felis & Cats & Small intestine & Xiao and Feng ${ }^{87}$ \\
\hline C. canis & Dogs & Small intestine & Fayer et al. ${ }^{88}$ \\
\hline C. ubiquitum & Cattle, Ruminants, rodents, primates & Intestine & Fayer et al. ${ }^{1}$ \\
\hline C. muris & House mouse, Rodents & Stomach & Tyzzer apud Xiao ${ }^{17}$ \\
\hline C. viatorum & Human & Small intestine & Elwin et al. ${ }^{89}$ \\
\hline C. cuniculus & European rabbits & Intestine & Robinson et al. ${ }^{90}$ \\
\hline C. andersoni & Cattle & Abomasum & Lindsay et al. ${ }^{91}$ \\
\hline C. suis & Pigs & Small and large intestine & Ryan et al. ${ }^{92}$ \\
\hline C. bovis & Cattle & Small intestine & Fayer et al. ${ }^{93}$ \\
\hline C. erinacei & European hedgehog, horses & & Kvác et al. ${ }^{94}$ \\
\hline C. scrofarum & Pig & Intestine & Kvác et al. ${ }^{95}$ \\
\hline C. tyzzeri & Mouse, Rodents & Small intestine & Tyzzer $^{17} ;$ Ren et al. ${ }^{96}$ \\
\hline C. xiaoi & Sheep and goats & & Fayer and Santín ${ }^{97}$ \\
\hline C. fayeri & Kangaroo, Marsupials & Small intestine & Ryan et al..$^{98}$ \\
\hline
\end{tabular}

Adapted from: Xiao et al. ${ }^{14}$ and Ryan et al. ${ }^{58} .{ }^{*}$ Chipmunk genotype I; Skunk genotype; Mink genotype; Horse genotype 
repetitions that allow categorizing C. parvum, C. hominis, Cryptosporidium ubiquitum, Cryptosporidium andersoni and Cryptosporidium meleagridis in families, according to the different subtypes. It is the marker with the largest polymorphism identified so far in the genome of Cryptosporidium spp. ${ }^{18-20}$. The gp60 gene encodes a GP60 protein that is located on the surface of the apical region of invasive stages of the parasite and is one of the main targets of neutralizing antibody responses in humans ${ }^{21}$. The distribution of families and subtypes of the Cryptosporidium species, mainly C. parvum and C. hominis, is still under investigation, with some results from different regions of the world. The following subtypes have been identified within Cryptosporidium species: 10 subtypes for C. hominis (Ia Ik); 19 subtypes for C. parvum (IIa - IIt) and 10 subtypes for C. meleagridis ${ }^{22-25}$. In relation to $C$. hominis, the $\mathrm{Ib}$ family is dominant in England, Portugal and Australia ${ }^{26}$ and families Ia, Id and Ie are more common in Kenya, Malawi, India, Peru and the USA ${ }^{16}$. In South Africa, the families most commonly found are If, $\mathrm{Ib}, \mathrm{Id}^{27}$, the If family has also been found in some samples from Portuga ${ }^{26}$. Although $C$. hominis is considered a species of Cryptosporidium specific for humans, there are progressively more reports of this species in animals. C. hominis was detected in cattle ${ }^{28}$, sheep and goats ${ }^{29}$, kangaroos $^{30}$, rodents $^{31}$ and $\operatorname{dog} s^{32}$, with the cosmopolitan subtype IbA10G2, associated with animal infection and being the dominant subtype in humans within these $\operatorname{areas}^{33}$. In addition to the 18S rRNA and gp60 gene targets, other genes have been used as tools in the search for the molecular characterization of Cryptosporidium species and subtypes, in line with several molecular techniques to detect these targets (Table 2).

In humans, a Cryptosporidium spp. infection may be asymptomatic, with mild clinical signs in the form of spontaneous diarrhea, or more severe symptoms with approximately 20 evacuations a day. The most serious clinical conditions are seen in immunocompromised individuals, including patients with immunological deficiencies related to malnutrition, patients undergoing chemotherapy, HIV-AIDS patients and transplant recipient patients ${ }^{34,35}$. In healthy individuals, the incidence of cryptosporidium infections is higher in children and in the elderly due to the natural immunocompromising that exists in these age groups. In these individuals, cryptosporidiosis can turn into a chronic disease that lasts for months or even years. In AIDS patients, cryptosporidiosis can be extremely severe, with mortality rates as high as $50 \%$. Additionally, cases of extra-intestinal cryptosporidiosis may occur, involving the hepatobiliary tract, lungs and pancreas. Biliary cryptosporidiosis is the most common manifestation after intestinal infection and has been described in $26 \%$ of AIDS
Table 2 - Molecular epidemiology and diagnosis tools for Cryptosporidium genotyping and subtyping.

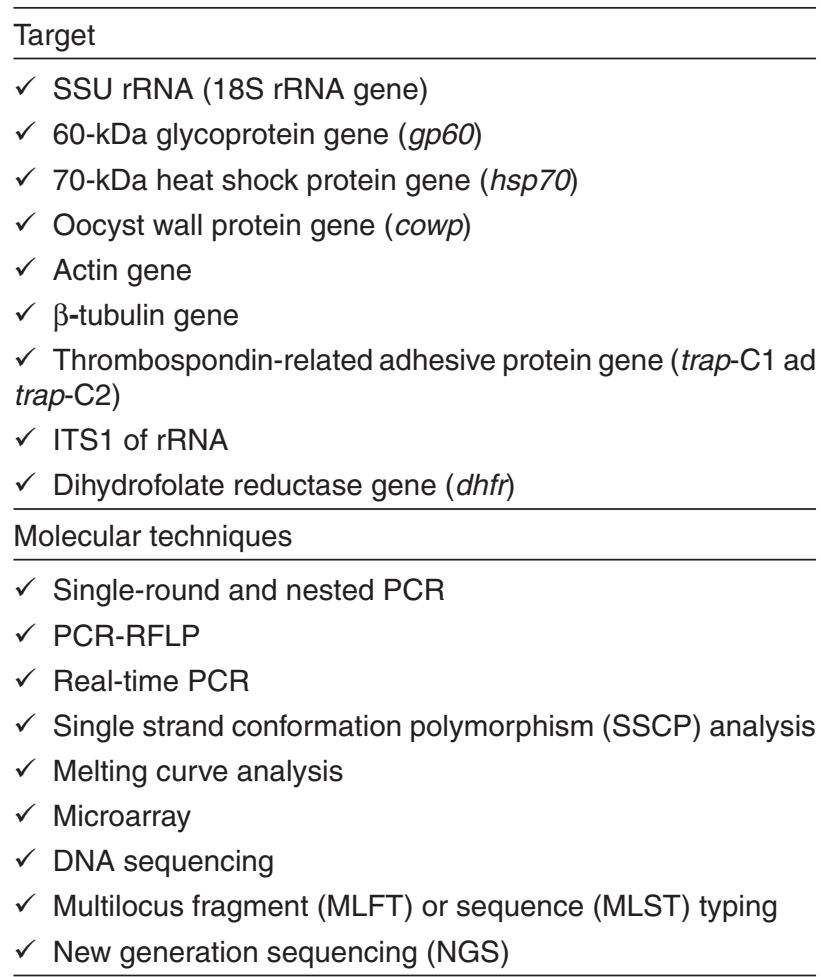

Adapted from unpublished data of Ana Luz Galvan.

patients $^{36}$. Respiratory tract infection is rare or may be underdiagnosed due to the lack of specific investigation. This infection is characterized by cough, dyspnea, fever and chest pain and may present radiological abnormalities similar to the ones of other pulmonary infections ${ }^{37}$.

\section{Laboratory diagnosis}

The laboratory diagnosis of human cryptosporidiosis can be performed by detection methods of the parasite such as optical microscopy, antigens or genetic material detection, as well as detection of antibodies against Cryptosporidium spp.

For a long time, the diagnosis of Cryptosporidium spp. was based only on the parasitological examination of stool samples (SPE), in which parasite oocysts were concentrated by flotation or centrifugation-sedimentation techniques. Immunological techniques for the detection of antigens in stool samples have also had a positive impact on diagnosis sensitivity using monoclonal antibodies in ELISA or Immunochromatographic assays ${ }^{38}$. Serum antibody detection may also be performed, but this method has a lower diagnostic efficiency than antigen detection. The use of monoclonal antibodies has also significantly improved 
the parasite detection in environmental samples, allowing the development of oocyst purification techniques such as paramagnetic beads conjugated to anti-Cryptosporidium monoclonal antibodies and fluorescence detection ${ }^{39}$. However, these methods do not allow Cryptosporidium spp. species identification in samples. Molecular methods for the detection of parasite-specific DNA sequences were developed and allowed not only an extensive revision of the taxonomy, but also an improvement in the laboratory diagnosis, with definition of species and subtypes within these species in the samples.

\section{Stool parasitological examination}

The method of stool samples concentration for detection by optical microscopy aimed to increase the finding of parasites in these samples by examining density differences between different compounds present in feces, such as fats and debris, which can make visualization of the parasite difficult. The most common oocyst concentration techniques are flotation in saturated sucrose solution and sedimentation by means of ether-formalin and acetate-formalin gradients ${ }^{39}$. For a better visualization of oocysts, light field or phase contrast optical microscopy are recommended ${ }^{40}$. Oocysts are visualized as bright bodies containing black granules, when using phase contrast, while in a light field microscope, the oocysts appear translucent, often as slightly pinkish structures, containing granules in their interior. The simple centrifugation-flotation method, also called centrifugationflotation in a hyper-saturated sucrose solution (Sheather's solution), was developed in 1923 with the objective of promoting the identification of parasitic forms in animal feces. This technique uses a high density sucrose solution to promote the separation of of protozoa cysts and coccidian oocysts, while using centrifugation as a way to promote the sedimentation of debris, forcing the fluctuation of parasitic structures so that they can be recovered later. In the centrifugation-flotation technique, another solute such as zinc sulphate can be used to promote the density gradient and fluctuation of parasitic evolutionary forms such as cysts and oocysts. Concentration techniques are always followed by staining methods, facilitating cysts observation. Staining techniques used in coccidia studies include the Kinyoun, Ziehl-Neelsen, negative staining, safranin, methylene blue, modified staining of Koster, Auramina and others ${ }^{41}$. The hot-resistant acid staining methods continue to be the most used for the identification of Cryptosporidium spp. oocysts $^{15}$ due to the low cost, easy execution and better setting of dyes. The morphological analysis of oocysts is not definitive for the identification of Cryptosporidium species because oocysts are very small $(4-8 \mu \mathrm{m})$, they may have imperceptible morphological variations, or even be identical between different species ${ }^{42}$. The oocysts size can also impair their visualization, so that it is extremely important to raise the sensitivity of these staining techniques. The intermittent elimination of cysts in feces and the need to be carried out by well-trained professionals to detect and identify the parasite, are also factors that impair the sensitivity of this technique for morphological analysis. False-positive results may also occur due to mistaken identification of fat bubbles and yeasts that can stain like Cryptosporidium spp. Other stains that can used in coccidia research are Malachite Green, Giemsa, Auramine, Nigrosin and Light Green ${ }^{15}$. However, these dyes do not have a well-known sensitivity and specificity, which makes it difficult to standardize the diagnostic routine for these protozoa in different clinical laboratories ${ }^{43}$. The histopathological examination, with autopsy and biopsy materials, can also be routinely used, aiding in the identification of the parasite and allowing the observation of the parasite evolutionary forms ${ }^{44}$.

For visualization of Cryptosporidium in tissues, the commonly used staining method is the hematoxylin-eosin in which the evolutionary forms are visualized as basophilic spherical bodies, from 2.0 to $7.5 \mu \mathrm{m}$, located on the surface of epithelial cells in histological sections. Other techniques that may be used are Schiff periodic acid and silver-based stains. Transmission electron microscopy allows the parasites' ultrastructural morphology visualization ${ }^{45}$.

Although Cryptosporidium spp. detection is primarily based on fresh or formalin-preserved fecal examination, the parasitological diagnosis has several limitations: it is timeconsuming, requires an experienced microscopist to identify organisms and may exhibit limited sensitivity when there are few oocysts in fecal samples. In addition, this method is not useful for evaluating samples subjected to unfavourable conditions, such as frozen stool or environmental samples, which may modify the parasite morphology ${ }^{46}$. Importantly, the microscopic methods do not allow the identification of species or genotypes involved in the infection.

\section{Immunological methods}

Immunological tests for antigen detection are simple, fast and specific. Despite having a higher cost, immunological tests require the use of monoclonal antibodies raised to specific targets for species differentiation and they present excellent sensitivity compared to the traditional staining techniques. The detection of antigens in feces (coproantigens) has become a useful tool in diagnosing cases of a suspected infection resulting from Entamoeba histolyticalEntamoeba dispar, Giardia lamblia and Cryptosporidium spp., whose fecal elimination usually 
occurs intermittently. Immunological assays, such as the indirect immunofluorescence can also be used to identify Cryptosporidium spp. in water samples ${ }^{47}$. In this case, variable volumes of water are required for analysis depending on the water samples type when using filtration followed by concentration, increasing the sensitivity of oocysts detection by fluorescence-labeled monoclonal antibodies and DAP (4',6'-diamidino-2-phenylindole $)^{48,49}$.

Detection of antibodies in serum samples from infected individuals can also be performed but presents problems due to difficulties in differentiating between a prior infection and a current infection, therefore decreasing the test value when samples from individuals in endemic areas with high parasite circulation are examined ${ }^{39}$.

The identification of species through the production of antibodies against oocyst wall antigens is also hampered by the presence of conserved antigens among different species within the genus Cryptosporidium. To overcome this difficulty, molecular methods with sensitive and specific detection of DNA fragments from the parasite have been developed.

\section{Detection of genetic material}

The detection of etiological agents genetic material has become a tool in the diagnosis of infectious diseases and to understand the epidemiology and taxonomy of etiological agents, including Cryptosporidium spp., characterizing different genotypes and subtypes ${ }^{9,17,50}$. According to $\mathrm{Smith}^{15}$, the taxonomy can incorporate genetic data as one of the parameters to validate Cryptosporidium species, with the application of molecular techniques.

The molecular methods currently used in the characterization of Cryptosporidium spp. are based on the polymerase chain reaction (PCR): nested-PCR, Single-Stranded Conformation Polymorphism PCR (PCRSSCP), DNA probes hybridization, Restriction Fragment Length Polymorphism PCR (PCR-RFLP), multiplex-PCR and real-time $P_{C R}{ }^{17}$. These techniques are generally associated with sequencing of amplified fragments for results confirmation ${ }^{17,39}$ and to analyze the genetic diversity between species. These methods use several genetic markers, among them, the most reported in the literature are the small subunit rRNA (SSU) gene that encodes the smaller ribosomal subunit of $18 S$ rRNA; the cowp gene, which encodes an oocyst wall protein; the $h s p 70$ gene, which encodes the heat shock proteins; ITS-1 and ITS-2, corresponding to internal transcribed spacer regions of ribosomal DNA; the trap gene (Thrombospondin-related adhesive protein of Cryptosporidium), and the gene encoding the GP60 or GP15/40 glycoproteins ${ }^{14,16,17,51}$.
PCR-RFLP is a technique that consists of restriction enzymes or endonucleases to digest PCR products. These enzymes cleave the DNA at a specific site promoting its fragmentation in certain sizes so that the posterior analysis on agarose or polyacrylamide gel, resulting in different patterns according to the species of Cryptosporidium analyzed, allowing their identification. Xiao et al. ${ }^{51,52}$ standardized a protocol that differentiates almost all described species of Cryptosporidium using nested-PCR of the SSU rRNA gene and cleaving the products with the enzymes SspI, VspI and DdeI. The DdeI restriction enzyme differentiates Cryptosporidium muris from C. andersoni, while the first two differentiate $C$. parvum, $C$. hominis, $C$. meleagridis, Cryptosporidium canis and Cryptosporidium serpentis, all belonging to the old group known as $C$. parvum. The use of PCR-RFLP with the restriction enzymes $S s p I$ and $V s p I$ is reported in at least $60 \%$ of the publications on the molecular epidemiology of cryptosporidiosis ${ }^{17}$.

Real-time PCR is one of the most recent PCR method whose methodology employs fluorescent markers. Verweij et al. ${ }^{53}$ described a real-time multiplexing method for the detection of Giardia lamblia, Entamoeba histolytica and C. parvum. The results of this study demonstrated $100 \%$ specificity and sensitivity of the technique. The authors stated that real-time PCR, using probes, can reduce the risk of contamination, as well as processing time and cost of reagents due to the possibility of detecting different targets in the same assay. The technique developed by Ramirez et $a l .{ }^{54}$ can diagnose the species of $C$. hominis, C. parvum, $C$. canis, Cryptosporidium felis and C. meleagrides only using the melting curve. Melting points have a difference between species of at least $1{ }^{\circ} \mathrm{C}$. The authors considered that the high specificity of the experiment is due to the small size (272 bp) of the amplified product, which lowers the melting temperature and increases the sensitivity of the test when compared to other protocols that amplify larger fragments. More recently, the real-time PCR method for detection of the genus Cryptosporidium and differentiation of $C$. hominis and C. parvum species using TaqMan probes from the 18S rRNA gene region was described and this methodology has also been used in our studies showing high efficiencies ${ }^{55,56}$.

Direct DNA sequencing is considered the "gold standard" for the evaluation of polymorphisms and the genetic variability of a given gene, in addition to enabling analysis of phylogeny in comparative genetic investigations ${ }^{15}$. Some studies have shown the genetic variability among species of Cryptosporidium. The first analysis on the comparison between the genetic sequences of $C$. hominis and C. parvum was carried out by Morgan et al. ${ }^{57}$. The authors recognized discriminatory regions, including the TTTTTTTTTTT sequence in $C$. hominis and 
the TATATTT sequence in $C$. parvum. They observed that the sequences are rich in bases A and T. Years later, these results were confirmed in another phylogenetic study of Cryptosporidium ${ }^{14}$. They stated that the sequences of $C$. hominis and C. parvum showed differences in four regions of the $18 S r R N A$ gene and that these differences were found in the first half of the gene sequence. The introduction of molecular tools has not only produced new insights into the epidemiology of cryptosporidiosis, but has also led to the identification of common modes of transmission such as zoonotic or anthroponotic transmission via the fecal-oral route and via contaminated food or water ${ }^{14,16,58}$.

\section{Cryptosporidium spp infection in Brazil}

In Brazil, there are few reports on Cryptosporidium spp. outbreaks in humans, all of them are in nurseries and most of them are in the Sao Paulo State ${ }^{59,60}$ (Figure 1). Usually, the cases are not properly documented as it is not an infection of obligatory notification in health services (Brazil Information System for Notifiable Diseases/Ministry of Health, Brazil). However, several studies have reported the presence of cysts and oocysts in water sources used for human supply ${ }^{61-63}$. Although the origin of these outbreaks have not yet been identified, environmental contamination in different regions of the country has been described in several types of water sources such as surface and groundwater, treated water from natural sources, natural waters from mineral sources, raw sewage and treated, hospital sewage. For this reason, since
2000, the Brazilian Ministry of Health recommends the inclusion of Cryptosporidium spp. investigation in drinking water analysis ${ }^{64}$. Recently, monitoring Cryptosporidium oocysts and Giardia cysts in water collection points has become mandatory when the annual geometric mean of Escherichia coli exceeds 1,000 CFU/ $100 \mathrm{~mL}$ considering a minimum number of 24 samples collected uniformly for a minimum period of one year and maximum of two years. The obligation to maintain a systematic evaluation of water supply systems, from the perspective of health risks with the implementation of the Water Safety Plan has also been established $^{65}$.

In a study carried out in Porto Alegre, Rio Grande do Sul State, the knowledge about this parasitic infection was evaluated among medical doctors. Of the 91 physicians interviewed, 83 (91.20\%) admitted that they needed more information on the disease. This result suggests that the prevalence of cryptosporidiosis in Brazil is underestimated, since few laboratories of parasitology are concerned with a surveillance of this parasite by using routine techniques and they only perform tests upon medical request ${ }^{37}$.

In Brazil, studies on cryptosporidiosis carried out in the last two decades have shown heterogeneity in the selection of sample population, methods of conservation and analysis of fecal samples, as well as the choice of molecular characterization methods ${ }^{2}$. Using classical microscopy techniques, Mangini et al. ${ }^{66}$ studied parasitism by Cryptosporidium spp. in children with acute diarrhea in the city of Sao Paulo. From 1987 to 1990, 241 fecal samples

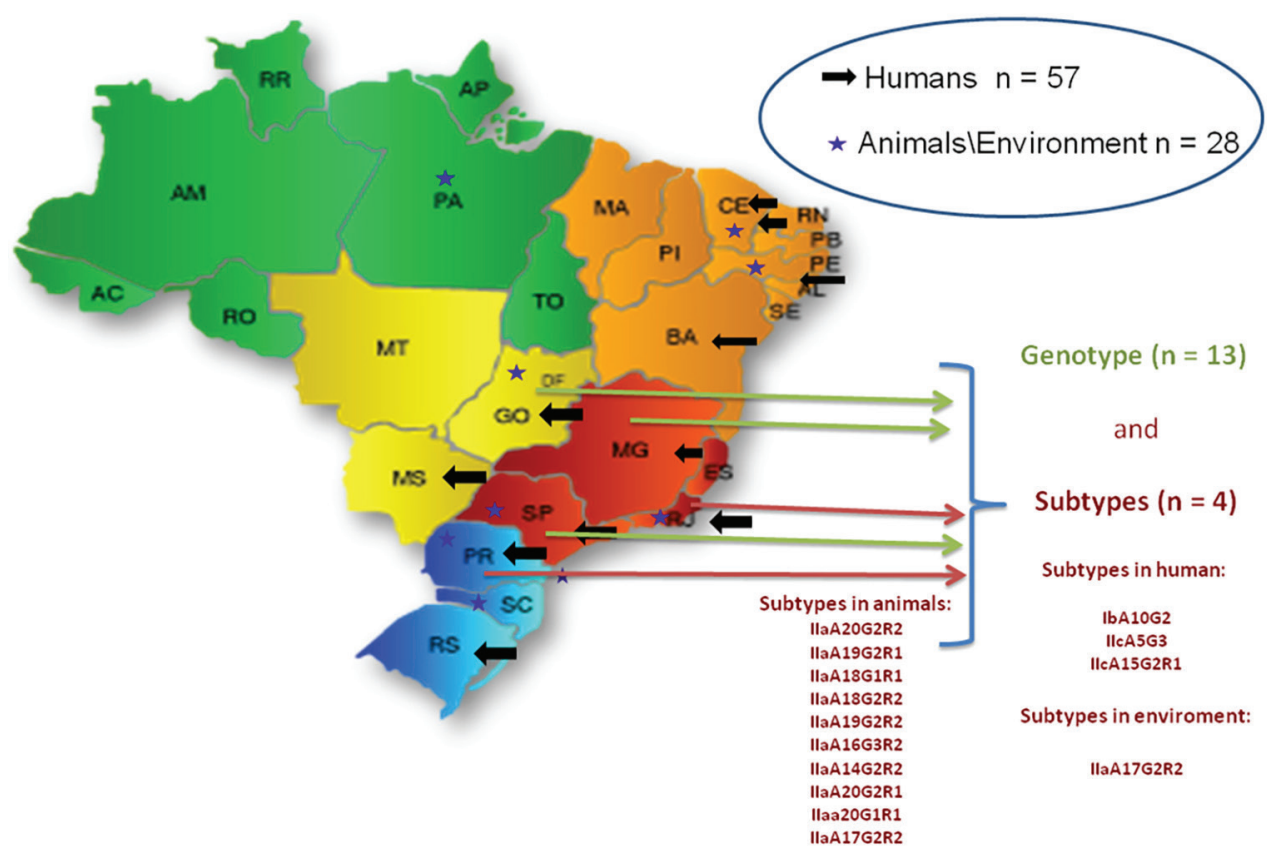

Figure 1 - Number of scientific articles published using detection methods and/or molecular characterization of Cryptosporidium in different regions of Brazil. (Data obtained until October 2018 in PubMed). 
were examined, of which $17.43 \%$ revealed the presence of Cryptosporidium spp. oocysts, and infections occurred more frequently in children aged 6 to 12 months. In this study, as in other countries, a trend of seasonal variation in the occurrence of cryptosporidiosis was observed, since the frequency of children treated with diarrhea was higher between March and May. In the municipality of Uberlandia, Minas Gerais State, the frequency of oocysts of Cryptosporidium spp. in diarrheal stools of children was $4.26 \%$ in a total of 94 samples $^{67}$. The report of Agnew et al. ${ }^{68}$ evidenced the city of Fortaleza, Ceara State, as an endemic region for Cryptosporidium spp., with a high seropositivity rate among samples from children and adults. Oshiro et al. ${ }^{69}$ studied the prevalence of Cryptosporidium spp. in children under 5 years old, living in the urban area of Campo Grande, Mato Grosso do Sul State, and found 1.1\% of infections and the highest frequency of the parasite $(50 \%)$ was found in children aged 25 to 36 months. A study carried out in Ribeirao Preto, Sao Paulo State, revealed a frequency of $1.8 \%$ of Cryptosporidium spp. among children 0 to 11 years of age ${ }^{70}$. In Santa Catarina State, Cryptosporidium spp. was also the most frequent enteroparasite $(85.1 \%)$ in children from 0 to 5 years of age $^{71}$.

A study by Newman et al. ${ }^{72}$ investigated environmental sources of Cryptosporidium spp. in Northeast Brazil. Water and animal samples were collected at different times of the year to evaluate the seasonal variation of cryptosporidiosis in the region. The results showed a higher incidence in fecal samples of animals (14.4\%) during the humid season, compared to the dry season (6.3\%). In the water samples, the presence of Cryptosporidium spp. was high, reaching $22.2 \%$, corroborating the role of animals as potential reservoirs of risk for environmental contamination. Franco et $a l . .^{73}$ analyzed water samples from the Atibaia River in Campinas, Sao Paulo State, with samples collected in three consecutive weeks, and observed that all of them were positive for Cryptosporidium spp. The presence of oocysts in water samples was investigated in Itaquaquecetuba, Sao Paulo State, and it was observed that 8 of the 10 analyzed samples were positive for the parasite. These results reinforce the understanding that Brazil's water must be protected from various forms of contamination, since it is an important natural vehicle for infections, including Cryptosporidium spp. ${ }^{74,75}$. In 2000, the Ministry of Health issued the order $\mathrm{N}^{\circ} 1469$ regulating the control of water for the presence of pathogenic organisms, such as cyanobacteria and fecal coliforms. In March 25, 2004, a new order $\mathrm{N}^{\circ} 518$ emerged with the recommendation of investigation of pathogenic organisms in drinking water and increased the range of surveyed organisms including Giardia lamblia cysts and Cryptosporidium spp. oocysts.
A few epidemiological studies developed in Brazil have used molecular methods for the detection of Cryptosporidium spp., as well as genotyping studies of their species and sub-types $^{76,77}$ (Figure 1). A study in Rio de Janeiro, Rio de Janeiro State, analyzed 26 samples of feces contaminated with Cryptosporidium spp. from children and immunocompromised patients. The PCR-RFLP technique revealed the presence of $C$. hominis and $C$. parvum, with C. hominis being the most frequent ${ }^{76}$. Gonçalves et al. ${ }^{60}$ performed a genotyping study of Cryptosporidium spp. associated with a diarrhea outbreak in Sao Paulo, Sao Paulo State, using the sequence of three different locus (SSU rRNA, cowp gene and ML1 microsatellite) and observed through the ML1 results that $C$. hominis was the only genotype identified in the 29 analyzed samples. The molecular analysis reinforced the hypothesis that the transmission of $C$. hominis during the outbreak of diarrhea occurred through person-toperson transmission, fecal-oral route. Also, in Sao Paulo, two other studies carried out the molecular characterization of Cryptosporidium spp. isolates, and C. hominis was the dominant species, but C. parvum, C. felis, C. meleagridis and C. canis were also found ${ }^{77,78}$. Rolando et al. ${ }^{55}$, conducted a survey on fecal samples collected from 1999 to 2010 in the city of Rio de Janeiro, searching for Cryptosporidium spp. using optical microscopy and real-time PCR, which can detect the genus Cryptosporidium and differentiate between C. hominis and C. parvum. From a total of 1,207 samples, 48 (3.98\%) were positive for Cryptosporidium spp. based on light microscopy results and amplification by a real-time PCR with a genus-specific probe. Of these 48 samples, (77.08\%) showed amplification for $C$. hominis and $5(10.42 \%)$ showed amplification for $C$. parvum. The six (12.50\%) samples that amplified only the genus, probably belonged to other species also found in human infections.

Peralta et $a l .{ }^{56}$ aimed to to better understand the main species present in clinical specimens from three public hospitals in Rio de Janeiro, Rio de Janeiro State. The group worked with 90 samples from patients of these hospitals who presented a requisition for coccidia investigation. All samples, independent of microscopy results, were analyzed by real-time PCR. Of these samples, $19.1 \%$ were positive for Cryptosporidium spp. under microscopy, while real-time PCR showed amplification for Cryptosporidium spp. in 4.5\% of the samples, for $C$. hominis in $15.7 \%$ of the samples and for C. parvum in $4.5 \%$ of the samples. Amplification was observed for these two species in a single sample. In these samples, nested-PCR for the $18 S$ rRNA and nested-PCR for gp60 were also carried out. Only $22.2 \%$ of the samples amplified for the $18 S$ rRNAmgene, but there was agreement with the real-time PCR in the definition of species, and $72 \%$ of the samples amplified for the gp60 gene. Analysis 
of the gp60 gene fragment identified the subtype IbA10G2 in all samples of $C$. hominis and the subtype IIcA5G3 (anthroponotic nature) for the samples with $C$. parvum. According to some authors, these subtypes are cosmopolitan and the IbA10G2 is considered the most virulent ${ }^{14,16,33,79,80}$.

The studies with environmental and animal samples are more advanced, as some studies performed the molecular characterization of species and sub-types of Cryptosporidium in both, water and soil samples, as well as in farm animals, birds, captive animals, reptiles, etc. These studies represent a major advance in the understanding of the anthropozoonotic transmission and for the development of preventive strategies to avoid environmental and human contamination. Cryptosporidiosis has a wide distribution in animals (farmed animals, confined animals, wild animals, etc.) based on observations of cryptosporidiosis reported in the literature ${ }^{59,81-83}$.

The main source of this parasite in the environment is the spread of feces from various animals. According to Graczyc et al. ${ }^{84}$, migratory birds fly in flocks and travel long distances, contributing to the environmental dissemination of infectious agents. Significant evidence indicates that birds play an important role in the transmission cycle of parasites, since in addition to migrating, they also reproduce and defecate in water sources and can contaminate important reservoirs $^{84,85}$. However, the studies performed in Brazil, regarding the presence of Cryptosporidium spp. in animals kept in captivity, are case reports with genus identification of the protozoan, and a few reports on the genotypes and subtypes, making it impossible to infer on zoonotic transmission possibilities, identification of the sources of infection or the epidemiology of the parasite in these environments. The same is true in free-living animals in both, wild and urban environments, as well as pet stores and animals that are kept in wildlife centers and zoos.

The lack of information on domestic animals is troubling, especially for the understanding of the relationship between animal and human contamination and what is interfering with the environment. These studies may provide information regarding the infectivity, as well as the virulence of the parasite. Therefore, future research is necessary to determine the susceptibility of different groups of hosts to Cryptosporidium spp in Brazil.

The diagnosis of cryptosporidiosis has been showing high sensitivity and specificity, at a moderate cost. This is a reality, but adequate political reforms must be implemented to allow access to a precise result, especially in patients in whom the differential diagnosis is unpredictable for the maintenance of life. The use of real-time PCR, together with microscopy and immunochromatography techniques, would result in a more precise diagnosis of cryptosporidiosis.
The analysis of genotypes, subtypes and clonality of Cryptosporidium could be helpful to understand and define the prognosis and severity of the infection.

\section{ACKNOWLEDGMENTS}

This work was supported by grants from the following Brazilian agencies: Coordenação de Aperfeiçoamento de Pessoal de Nivel Superior (CAPES), Conselho Nacional de Desenvolvimento Científico e Tecnológico (CNPq) and Fundação Carlos Chagas Filho de Amparo à Pesquisa do Estado do Rio de Janeiro (FAPERJ).

\section{CONFLICT OF INTERESTS}

The authors have no conflict of interests in this study

\section{AUTHORS' CONTRIBUTIONS}

All authors prepared the bibliographic survey, manuscript preparation and approved the final version of the manuscript.

\section{REFERENCES}

1. Fayer R. Taxonomy and species delimitation in Cryptosporidium. Exp Parasitol. 2010;124:90-7.

2. Meireles MV. Cryptosporidium infection in Brazil: implications for veterinary medicine and public health. Rev Bras Parasitol Vet. 2010;19:197-204.

3. Baldursson S, Karamis P. Waterborne transmission of protozoan parasites: review of world outbreaks - an update 2004-2010. Water Res. 2011;45:6603-14.

4. Fayer R. Cryptosporidium: a waterborne zoonotic parasite. Vet Parasitol. 2004;126:37-56.

5. Paparini A, Gofton A, Yang R, White N, Bunce M, Ryan UM. Comparison of Sanger and next generation sequencing performance for genotyping Cryptosporidium isolates at the 18S RNA and actin loci. Exp Parasitol. 2015;151-152:21-7.

6. Carreno RA, Matrin DS, Barta JR. Cryptosporidium is more closely related to the gregarines than to coccidia as shown by phylogenetic analysis of apicomplexan parasites inferred using small-subunit ribosomal RNA gene sequences Parasitol Res. 1999;85:899-904

7. Karanis P, Kimura A, Nagasawa H, Igarashi I, Suzuki N. Observations on Cryptosporidium life cycle stages during excystation. J Parasitol. 2008;94:298-300.

8. Karanis P, Aldeyarbi HM. Evolution of Cryptosporidium in vitro culture. Int J Parasitol. 2011;41:1231-42.

9. Clode PL, Koh WH, Thompson RC. Life without a host cell: what is Cryptosporidium? Trends Parasitol. 2015;31:614-24. 
10. Cavalier-Smith T. Gregarine site-heterogeneous $18 \mathrm{~S}$ rDNA trees, revision of gregarine higher classification, and the evolutionary diversification of Sporozoa. Eur J Protistol. 2014;50:472-95.

11. Thompson RC, Koh WH, Clode PL. Cryptosporidium: what is it? Food Waterborne Parasitol. 2016;4:54-61.

12. Hijjawi N, Estcourt A, Yang R, Monis P, Ryan U. Complete development and multiplication of Cryptosporidium hominis in cell free culture. Vet Parasitol. 2010;169:29-36.

13. Koh W, Thompson RC, Edwards H, Monis P, Clode PL. Extracellular excystation and development of Cryptopsoridium: tracing the fate of oocysts within Pseudomonas aquatic biofilm systems. BMC Microbiol. 2014;14:281.

14. Xiao L, Feng Y. Molecular epidemiologic tools for waterborne pathogens Cryptosporidium spp. and Giardia duodenalis. Food Waterborne Parasitol. 2017;8-9:14-32.

15. Smith H. Diagnostics. In: Fayer R, Xiao L, editors. Cryptosporidium and Cryptosporidiosis. $2^{\text {nd }}$ ed. Boca Raton: CRC Press; 2008. p.173-208.

16. Khan A, Shaik JS, Grigg ME. Genomics and molecular epidemiology of Cryptosporidium species. Acta Trop. 2018;184:1-14.

17. Xiao L. Molecular epidemiology of Cryptosporidiosis: an update. Exp Parasitol. 2010;124:80-9.

18. Wielinga PR, de Vries A, van der Goot TH, Mank T, Mars MH, Kortbeek LM, et al. Molecular epidemiology of Cryptosporidium in humans and cattle in The Netherlands. Inter J Parasitol. 2008;38:809-17.

19. Laatamna AE, Wagnerová P, Sak B, Květoňová D, Xiao L, Rost $\mathrm{M}$, et al. Microsporidia and Cryptosporidium in horses and donkeys in Algeria: detection of a novel Cryptosporidium hominis subtype family (Ik) in a horse. Vet Parasitol. 2015;208:135-42.

20. Prediger J, Horčičková M, Hofmannová L, Sak B, Ferrari N, Mazzamuto MV, et al. Native and introduced squirrels in Italy host different Cryptosporidium spp. Eur J Protistol. 2017;61:64-75.

21. O'Connor RM, Wanyiri JW, Cevallos AM, Priest JW, Ward HD. Cryptosporidium parvum glycoprotein gp40 localizes to the sporozoite surface by association with gp15. Mol Biochem Parasitol. 2007;156:80-3.

22. Abe N, Matsubayashi M, Kimata I, Iseki M. Subgenotype analysis of Cryptosporidium parvum isolates from humans and animals in Japan using the $60-\mathrm{kDa}$ glycoprotein gene sequences. Parasitol Res. 2006;99: 303-5.

23. Glaberman S., Sulaiman IM, Bern C, Limor J, Peng MM, Morgan $\mathrm{U}$, et al. A multilocus genotypic analysis of Cryptosporidium meleagridis. J Eukaryot Microbiol. 2001;Suppl:19S-22S.

24. Misic Z, Abe N. Subtype analysis of Cryptosporidium parvum isolates from calves on farms around Belgrade, Serbia and Montenegro, using the $60 \mathrm{kDa}$ glycoprotein gene sequences. Parasitology. 2007;134:351-8.
25. Soba B, Logar J. Genetic classification of Cryptosporidium isolates from humans and calves in Slovenia. Parasitology. 2008;135:1263-70.

26. Alves M, Xiao L, Antunes F, Matos O. Distribution of Cryptosporidium subtypes in humans and domestic and wild ruminants in Portugal. Parasitol Res. 2006;99:287-92.

27. Leav BA, Mackay MR, Anyanwu A, O' Connor RM, Cevallos AM, Kindra G, et al. Analysis of sequence diversity at the highly polymorphic Cpgp40/15 locus among Cryptosporidium isolates from human immunodeficiency virus-infected children in South Africa. Infect Immunol. 2002;70:3881-90.

28. Wang ZD, Liu Q, Liu HH, Li S, Zhang L, Zhao YK, et al. Prevalence of Cryptosporidium, microsporidia and Isospora infection in HIV-infected people: a global systematic review and meta-analysis. Parasit Vectors. 2018;11:28.

29. Kaupke A, Gawor J, Rzeżutka A, Gromadka R. Identification of pig-specific Cryptosporidium species in mixed infections using Illumina sequencing technology. Exp Parasitol. 2017;182:22-5.

30. Zahedi A, Monis P, Gofton AW, Oskam CL, Ball A, Bath A, et al. Cryptosporidium species and subtypes in animals inhabiting drinking water catchments in three states across Australia. Water Res. 2018;134: 327-40.

31. Danisová O, Valencaková A, Stanko M, Luptáková L, Hatalová E, Čanády A. Rodents as a reservoir of infection caused by multiple zoonotic species/genotypes of C. parvum, C. hominis, C. suis, C. scrofarum, and the first evidence of C. muskrat genotypes I and II of rodents in Europe. Acta Trop. 2017;172:29-35.

32. Gil H, Cano L, de Lucio A, Bailo B, de Mingo MH, Cardona GA, et al. Detection and molecular diversity of Giardia duodenalis and Cryptosporidium spp. in sheltered dogs and cats in Northern Spain. Infect Genet Evol. 2017;50:62-9.

33. Feng YY, Ryan UM, Xiao L. Genetic diversity and population structure of Cryptosporidium. Trends Parasitol. 2018;34:9971011.

34. Danziger-Isakov L. Gastrointestinal infections after transplantation. Curr Opin Gastroenterol. 2014;30:40-6.

35. Siddiqui ZA. An overview of parasitic infections of the gastro-intestinal tract in developed countries affecting immunocompromised individuals. J Parasit Dis. 2017;41:621-6.

36. Gao Y, Chin K, Mishriki, YY. AIDS cholangiopathy in an asymptomatic, previously undiagnosed late-stage HIV-positive patient from Kenya. Inter J Hepatol. 2011;2011:465895.

37. Albuquerque YM, Silva MC, Lima AL, Magalhães V. Pulmonary cryptosporidiosis in AIDS patients, in underdiagnosed disease. J Bras Pneumol. 2012;38:530-2.

38. McHardy IH, Wu M, Shimizu-Cohen R, Couturier MR, Humphries RM. Detection of intestinal protozoa in the clinical laboratory. J Clin Microbiol. 2014;52:712-20.

39. Khurana S, Chaudhary P. Laboratory diagnosis of cryptosporidiosis. Trop Parasitol. 2018;8:2-7. 
40. Kar S, Gawlowska S, Daugschies A, Bangoura B. Quantitative comparison of different purification and detection methods for Cryptosporidium parvum oocysts. Vet Parasitol. 2011;177:36670.

41. Ezzaty Mirhashemi M, Zintl A, Grant T, Lucy FE, Mulcahy G, De Waal T. Comparison of diagnostic techniques for the detection of Cryptosporidium oocysts in animal samples. Exp Parasitol. 2015;151-152:14-20.

42. Fall A, Thompson RC, Hobbs RP, Morgan-Ryan U. Morphology is not a reliable tool for delineating species within Cryptosporidium. J Parasitol. 2003;89:399-402.

43. Sodré FC, Franco RM. Novos aspectos sobre um tema bem conhecido: Cryptosporidium. Rev Bras Anal Clin. 2001;33:97-104.

44. Chalmers RM, Giles M. Zoonotic cryptosporidiosis in the UK: challenges for control. J Appl Microbiol. 2010;109:148797.

45. Valigurová A, Jirků M, Koudela B, Gelnar M, Modrý D, Šlapeta J. Cryptosporidia: epicellular parasites embraced by the host cell membrane. Int J Parasitol. 2008;38:913-22.

46. Jex AR, Smith HV, Monis PT, Campbell BE, Gasser RB. Cryptosporidium: biotechnological advances in the detection, diagnosis and analysis of genetic variation. Biotechnol Adv. 2008;26:304-17.

47. Neto RC, Santos LU, Sato MI, Franco RM. Cryptosporidium spp. and Giardia spp. in surface water supply of Campinas, southeast Brazil. Water Sci Technol. 2010;62:217-22.

48. Navarro-i-Martinez L, del Águila C, Bornay-Llinares FJ. Cryptosporidium: un género en révision. Situación en España. Enferm Infecc Microbiol Clin. 2011;29:135-43.

49. Galván AL, Magnet A, Izquierdo F, Fernandéz Vadillo C, Peralta $\mathrm{RH}$, Angulo S, et al. A year-long study of Cryptosporidium species and subtypes in recreational, drinking and wastewater from the central area of Spain. Sci Total Environ. 2014;468469:368-75.

50. Xiao L, Fayer R. Molecular characterization of species and genotypes of Cryptosporidium and Giardia and assessment of zoonotic transmission. Int J Parasitol. 2008;38:1239-55.

51. Ryan U, Fayer R, Xiao L. Cryptosporidium species in humans and animals: current understanding and research needs. Parasitology. 2014;141:1667-85.

52. Xiao L, Ryan UM. Cryptosporidiosis: an update in molecular epidemiology. Curr Opin Infect Dis. 2004;17:483-90.

53. Verweij JJ , Blangé RA, Templeton K, Schinkel J, Brienen EA, van Rooyen MA, et al. Simultaneous detection of Entamoeba histolytica, Giardia Lamblia and Cryptosporidium parvum in fecal samples by using multiplex real-time PCR. J Clin Microbiol. 2004;42:1220-3.

54. Ramirez NE, Sreevatsan S. Development of a sensitive detection system for Cryptosporidium in environmental samples. Vet Parasitol. 2006;136:201-13.
55. Rolando RF, Silva S, Peralta RH, Silva AJ, Cunha FS, Bello AR, et al. Detection and differentiation of Cryptosporidium by real-time polymerase chain reaction in stool samples from patients in Rio de Janeiro, Brazil. Mem Inst Oswaldo Cruz. 2012;107:476-9.

56. Peralta RH, Velásquez JN, Cunha FS, Pantano ML, Sodré FC, Silva S, et al. Genetic diversity of Cryptosporidium identified in clinical samples from cities in Brazil and Argentina. Mem Inst Oswaldo Cruz. 2016;111:30-6.

57. Morgan UM, Constantine CC, Forbes DA, Thompson RC. Differentiation between human and animal isolates of Cryptosporidium parvum using rDNA sequencing and direct PCR analysis. J Parasitol. 1997;83:825-30.

58. Ryan U, Hijjawi N, Xiao L. Foodborne cryptosporidiosis. Inter J Parasitol. 2018;48:1-12.

59. Carvalho TB, Carvalho LR, Mascarini, LM. Occurrence of enteroparasites in day care centers in Botucatu (São Paulo State, Brazil) with emphasis on Cryptosporidium sp., Giardia duodenalis and Enterobius vermicularis. Rev Inst Med Trop Sao Paulo. 2006;48:269-73.

60. Gonçalves EM, Silva AJ, Eduardo MB, Uemura IH, Moura IN, Castilho VL, et al. Multilocus genotyping of Cryptosporidium hominis associated with diarrhea outbreak in a day care unit in Sao Paulo. Clinics (Sao Paulo). 2006;61:119-26.

61. Osaki SC, Soccol VT, Costa AO, Oliveira-Silva MB, Pereira JT, Procópio AE. Polymerase chain reaction and nested-PCR approaches for detecting Cryptosporidium in water catchments of water treatment plants in Curitiba, State of Paraná, Brazil. Rev Soc Bras Med Trop. 2013;46:270-6.

62. Araújo RS, Aguiar B, Dropa M, Razzolini MT, Sato MI, Souza Lauretto M, et al. Detection and molecular characterization of Cryptosporidium species and Giardia assemblages in two watersheds in the metropolitan region of São Paulo, Brazil. Environ Sci Pollut Res Int. 2018;25:15191-203.

63. Sato MI, Galvani AT, Padula JA, Nardocci AC, Lauretto MS, Razzolini MT, et al. Assessing the infection risk of Giardia and Cryptosporidium in public drinking water delivered by surface water systems in Sao Paulo State, Brazil. Sci Total Environ. 2013;442:389-96.

64. Brasil. Ministério da Saúde. Gabinete do Ministro. Portaria $\mathrm{n}^{\circ} 2.914$ de 12 de dezembro de 2011. Dispõe sobre os procedimentos de controle e de vigilância da qualidade a água para consumo humano e seu padrão de potabilidade. [cited 2019 Apr 25]. Available from: http://bvsms.saude.gov.br/bvs/ saudelegis/gm/2011/prt2914_12_12_2011.html

65. Brasil. Ministério da Saúde. Gabinete do Ministro. Portaria de consolidação $n^{\circ} 5$, de 28 de setembro de 2017. Consolidação das normas sobre as ações e os serviços de saúde do Sistema Único de Saúde. [cited 2019 Apr 25]. Available from: http://bvsms. saude.gov.br/bvs/saudelegis/gm/2017/prc0005_03_10_2017. html 
66. Mangini AC, Dias RM, Grisi SJ, Escobar AM, Torres DM, Zuba IP, et al. Parasitismo por Cryptosporidium sp. em crianças com diarréia aguda. Rev Inst Med Trop Sao Paulo.1992;34:341-5.

67. Gennari-Cardoso ML, Costa-Cruz JM, Castro E, Lima LM, Prudente DV. Cryptosporidium sp. in children suffering from acute diarrhea at Uberlandia City, State of Minas Gerais, Brazil. Mem Inst Oswaldo Cruz. 1996;91:551-4.

68. Agnew DG, Lima AA, Newman RD, Wuhib T, Moore RD, Guerrant RL, et al. Cryptosporidiosis in northeastern Brazilian children: association with increased diarrhea morbidity. J Infect Dis. 1998;177:754-60.

69. Oshiro ET, Dorval ME, Nunes VL, Silva MA, Said LA. Prevalência do Cryptosporidium parvum em crianças abaixo de 5 anos, residentes na zona urbana de Campo Grande, MS, Brasil, 1996. Rev Soc Bras Med Trop. 2000;33:277-80.

70. Medeiros MI, Neme SN, Silva P, Capuano DM, Errera MC, Fernandes SA, et al. Etiology of acute diarrhea among children in Ribeirão Preto - SP, Brazil. Rev Inst Med Trop Sao Paulo. 2001;43:21-4.

71. Schnack FJ, Fontana LM, Barbosa PR, Silva LS, Baillargeon CM, Barichello T, et al. Enteropatógenos associados com diarréia infantil ( $<5$ anos de idade) em amostra da população da área metropolitana de Criciúma, Santa Catarina, Brasil. Cad Saude Publica. 2003;19:1205-8.

72. Newman RD, Wuhib T, Lima AA, Guerrant RL, Sears CL. Environmental sources of Cryptosporidium in an urban slum in northeastern Brazil. Am J Trop Med Hyg. 1993;49:270-5.

73. Franco RM, Rocha-Eberhardt R, Cantusio Neto R. Occurrence of Cryptosporidium oocysts and Giardia cysts in raw water from the Atibaia River, Campinas, Brazil. Rev Inst Med Trop Sao Paulo. 2001;43:109-11.

74. Gamba RC, Ciapina EM, Espíndola RS, Pacheco A, Pellizari VH. Detection of Cryptosporidium sp oocysts in groundwater for human consumption in Itaquaquecetuba city, S. Paulo - Brazil. Braz J Microbiol. 2000;31:151-3.

75. Franco RM. Protozoários de veiculação hídrica: relevância em saúde pública. Rev Panam Infectol. 2007;9:36-43.

76. Silva S, Silva SP, Gouveia YS, da Silva NO, Melo ME, Moura H, et al. Ocorrência de Cryptosporidium sp em amostras fecais de crianças, menores de 10 anos de idade, com indicação clínica de Rotavírus. Rev Soc Bras Med Trop. 2003;36:421-3.

77. Araújo AJ, Kanamura HY, Almeida ME, Gomes AH, Pinto TH, Silva AJ. Genotypic identification of Cryptosporidium spp. isolated from HIV infected patients and immunocompetent children of Sao Paulo, Brazil. Rev Inst Med Trop Sao Paulo. 2008;50:139-43.

78. Lucca P, De Gaspari EM, Bozzoli LM, Funada MR, Silva SO, Iuliano W, et al. Molecular characterization of Cryptosporidium spp. from HIV infected patients from an urban area of Brazil. Rev Inst Med Trop Sao Paulo. 2009;51:341-3.
79. Li N, Xiao L, Cama VA, Ortega Y, Gilman RH, Guo M, et al. Genetic recombination and Cryptosporidium hominis virulent subtype IbA10G2. Emerg Infect Dis. 2013;19:1573-82.

80. Adeyemo FE, Singh G, Reddy P, Stenström TA. Methods for the detection of Cryptosporidium and Giardia: from microscopy to nucleic acid based tools in clinical and environmental regimes. Acta Trop. 2018;184:15-28.

81. Silva DC, Paiva PR, Nakamura AA, Homem CG, Souza MS, Grego KF, et al. The detection of Cryptosporidium serpentis in snake fecal samples by real-time PCR. Vet Parasitol. 2014;204:134-8.

82. Holsback L, Lima HE, Vidotto O, Silva MA, Patelli TH, Martins FD, et al. Cryptosporidium occurrence in ruminants from the North Pioneer mesoregion of Paraná, Brazil. Rev Bras Parasitol Vet. 2018;27:248-53.

83. Sevá AD, Pena HF, Nava A, Sousa AO, Holsback L, Soares RM. Endoparasites in domestic animals surrounding an Atlantic Forest remnant, in São Paulo State, Brazil. Rev Bras Parasitol Vet. 2018;27:13-9.

84. Graczyk TK, Majewska AC, Schwab KJ. The role of birds in dissemination of human waterborne enteropathogens. Trends Parasitol. 2008;24:55-9.

85. Kassa H, Harrington BJ, Bisesi MS. Cryptosporidiosis: a brief literature review and update regarding Cryptosporidium in feces of Canada geese (Branta canadensis). J Environ Health. 2004;66:34-40

86. Slavin D. Cryptosporidium meleagridis (sp. nov.). J Comp Pathol. 1955;65:262-6

87. Xiao L, Feng Y. Zoonotic cryptosporidiosis. FEMS Immunol Med Microbiol. 2008;52:309-23.

88. Fayer R, Trout JM, Xiao L, Morgan UM, Lai AA, Dubey JP. Cryptosporidium canis n. sp. from domestic dogs. J Parasitol. 2001;87:1415-22.

89. Elwin K, Hadfield SJ, Robinson G, Crouch ND, Chalmers RM. Cryptosporidium viatorum n. sp. (Apicomplexa: Cryptosporidiidae) among travellers returning to Great Britain from the Indian subcontinent, 2007-2011. Int J Parasitol. 2012;42:675-82.

90. Robinson G, Wright S, Elwin K, Hadfield SJ, Katzer F, Bartley PM, et al. Re-description of Cryptosporidium cuniculus Inman and Takeuchi, 1979 (Apicomplexa: Cryptosporidiidae): morphology, biology and phylogeny. Int J Parasitol. 2010;40:1539-48.

91. Lindsay DS, Upton SJ, Owens DS, Morgan UM, Mead JR, Blagburn BL. Cryptosporidium andersoni n. sp. (Apicomplexa: Cryptosporiidae) from cattle, Bos taurus. J Eukaryot Microbiol. 2000;47:91-5.

92. Ryan UM, Monis P, Enemark HL, Sulaiman I, Samarasinghe B, Read C, et al. Cryptosporidium suis n. sp. (Apicomplexa: Cryptosporidiidae) in pigs (Sus scrofa). J Parasitol. 2004;90:769-73. 
93. Fayer R, Santín M, Xiao L. Cryptosporidium bovis n. sp. (Apicomplexa: Cryptosporidiidae) in cattle (Bos taurus). J Parasitol. 2005;91:624-9.

94. Kváč M, Hofmannová L, Hlásková L, Květoňová D, Vítovec J, McEvoy J, et al. Cryptosporidium erinacei n. sp. (Apicomplexa: Cryptosporidiidae) in hedgehogs. Vet Parasitol. 2014;;201:917.

95. Kváč $M$, Kestráánová $M$, Pinková $M$, Květoňová $D$, Kalinová J, Wagnerová P, et al. Cryptosporidium scrofarum n. sp. (Apicomplexa: Cryptosporidiidae) in domestic pigs (Sus scrofa). Vet Parasitol. 2013;191:218-27.
96. Ren X, Zhao J, Zhang L, Ning C, Jian F, Wang R, et al. Cryptosporidium tyzzeri n. sp. (Apicomplexa: Cryptosporidiidae) in domestic mice (Mus musculus). Exp Parasitol. 2012;130:274-81.

97. Fayer R, Santín M. Cryptosporidium xiaoi n. sp. (Apicomplexa: Cryptosporidiidae) in sheep (Ovis aries). Vet Parasitol. 2009;164:192-200.

98. Ryan UM, Power M, Xiao L. Cryptosporidium fayeri n. sp. (Apicomplexa: Cryptosporidiidae) from the Red Kangaroo (Macropus rufus). J Eukaryot Microbiol. 2008;55:22-6. 